HUNGARIAN AGRICULTURAL ENGINEERING

$N^{\circ} 37 / 202041-47$

Published online: http://hae-journals.org/

HU ISSN 0864-7410 (Print) / HU ISSN 2415-9751(Online)

DOI: 10.17676/HAE.2020.37.41

Received: 02.02.2020 - Accepted: 25.03.2020
PERIODICAL OF THE COMITTEE OF

AGRICULTURAL AND BIOSYSTEM

ENGINEERING OF

THE HUNGARIAN ACADEMY OF SCIENCES

and

SZENT ISTVÁN UNIVERSITY

Faculty of Mechanical Engineering

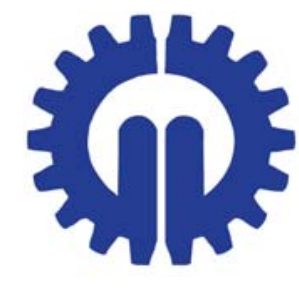

\title{
SMART CONTROL ON AGRICULTURAL MACHINES
}

\section{Author(s): \\ L. Magó}

Affiliation:

Szent István University, Faculty of Mechanical Engineering, Institute of Engineering Management, Department of Logistics and Materials Handling, Páter K. u. 1., Gödöllö, H-2103, Hungary

\section{Email address:}

Mago.Laszlo@gek.szie.hu

\begin{abstract}
Precision Agriculture technologies are efficient tools to improve sustainability and productivity in farming. These technologies offer solutions to produce more with less.

Nowadays the increasing of the efficiency of agricultural production and the increasing of crop yields cannot be achieved without modern digital technology and smart machines that are a part of it. Next to the power machines the attached equipment is becoming smarter and smarter.

In this work, without completeness, we present smart solutions from medium-sized innovative manufacturer of agricultural machines which are independent from the size of the machine and which are effective tools for the utilization of machines, for the precision machine work.
\end{abstract}

Keywords: smart machines, Precision Agriculture, GPS, spreading, variable rate fertilizing

\section{Introduction}

Many authors have reached to the conclusion that development of digital technology and applications are regarded as an important factor in their economic growth and development in the agricultural production. The improvement of mechanization of field work, machinery and equipment is a continuous process. We are witnessing the spread and agricultural use of the more and more modern equipment, which reflects to the technical and technological level of the area (Kovács and Husti 2018).

Precision Agriculture is just a hypernym and can be divided into three major topics Auernhammer (2002), "Precision Pasturing", "Precision Lifestock Farming" and "Precision (Crop) Farming". While Precision Pasturing focuses on methods for e.g. managing feed supply and stocking rates on pastures (Schellberg, et al. 2008), Precision Lifestock Farming addresses all kind of systems which correspond with animals in husbandry. The last topic, Precision Farming, is defined as technology-supported cultivation of agriculturally used areas (Doluschitz, et al. 2011). (Bauerdick, et al. 2017)

The aim of precision, or site specific agriculture is to handle within field variability (Auernhammer et al. 2001) with input materials to achieve the highest and sustainable profit. The approach mainly benefits from the development of technologies like GPS, GIS, computer technology, automatic control, remote sensing and advanced information processing (Gibbons 2000) Farm field under conventional management receive uniform applications of these inputs like fertilizers, herbicides, seed or irrigation. (Mulla 2013) (Büdi et al. 2018)

The most popular precision agricultural technologies are the grid soil sampling, the variable rate fertilizer applications, the global positioning systems and yield mapping and the variable rate seeding (Daberkow and McBride 1999, Mackay 1997, Taylor and Whelan 2010, Bullock et al. 1998, Clark and McGuckin 1996, Nafziger 2012).

The biggest problem with the precision farming technology is that the possible advantages and disadvantages of the technology highly depend on the professional knowledge and attitude of the farmers or of the manager and the stuff of the agricultural company. The appearance of a new technology in generally of great interest, the so co-called 'new technology fun' farmers try the application, invest in the new equipment - and very often without the proper knowledge, skill - they implement it into their farming. After the first experiments - if they have not got good yield and economic result - many of them give the new technology up, or did not 
continue the introduction and extension of the new item. The excessive expectation does not match with the reality. After the interest peak, there is almost temporary disillusionment. After the refinement of the technology, its applicability improves, instead of the risks, the benefits come to the fore, leading to its spread in production. (Takácsné 2018)

\section{Material and method}

\section{Smart Farming}

"Smart Agriculture" and "Digital Farming" are based on the emergence of smart technology in agriculture. These technologies are using smart devices which consist of sensors, actuators and communication technology (Kovács and Husti 2018).

Digital systems, sensor techniques and technologies, remote sensing on different platforms, artificial intelligence including machine learning and deep learning, and in particular unmanned or quasi unmanned production systems are developing fast, and these are the tool for dynamic sustainability. In the future there will be the integration of these common players into smart transport, smart organisation, and smart landscape management by smart policy making. (Lundström and Lindblom 2016, Urso et al. 2017, Kempenaar et al. 2016, Neményi 2018)

The Smart Logistic System, integrated with the ERP (Enterprise Resource Planning), enables application of 4.0 industry approach. Its intention is to enable same application to agricultural machinery, e.g. for logging the seeding and fertilizing process (lot, operator, date, quantity) and remote diagnostic by using IoT ready systems. The advantages of own production applied utilization of digital information to trace the different materials and automate their handling, are listed following objectives:

-to reduce the material handling;

-to reduce the inventory failures;

-to implement flexibility with discipline;

-to find one place for everything and everything in its place;

-to set a FIFO (First In First Out) rule;

-to implement the material traceability. (Martinov et al. 2018)

\section{The Company INO Brě̆ice d.o.o.}

A Slovenian company INO Brežice produces a variety of mulching machines, vibrating subsoilers, fertilizer spreaders. Among the company's innovative products are so-called "Smart Solutions" which ensure a safe and efficient operating of their basic products:

-flail mowers by means of continuous measuring vibrations and detecting the outstanding ones,

-fertilizer spreaders and vibrating subsoilers by efficient specific electronic control of operating. (Šubic 2017)

\section{Results}

\section{INO Smart Flow}

INO Smart Flow ensures the quality work of the FERTI-2 type double-disc mounted fertilizer spreader (Figure 1.) and the VVP 115 vibrational subsoiler with deep fertilizer spreader (Figure 2.). It is well known regarding versatility and an ease of use. Nowadays, site-specific nutrient application comes to the fore. Thus, accurate determination of the amount of fertilizer applied and precise dosing is essential. With this system cost savings can be achieved through efficient production and avoidance of excess nutrients.

INO Smart Flow electronic regulation of fertilizer flow on Ferti-2 is the system, which automatically regulates the position of both shutters on the bottom of the hopper. It is completely developed and designed in INO Electronic Department.The machine ensures equal spreading density ( $\mathrm{kg} / \mathrm{ha})$ across the spreading area, regardless of the working speed. At faster speed, the shutters must be more open than at lower speed. The 
optimal position of the shutters is calculated in the electronic box, based on the spreading width, speed of the tractor and fertilizer calibration.

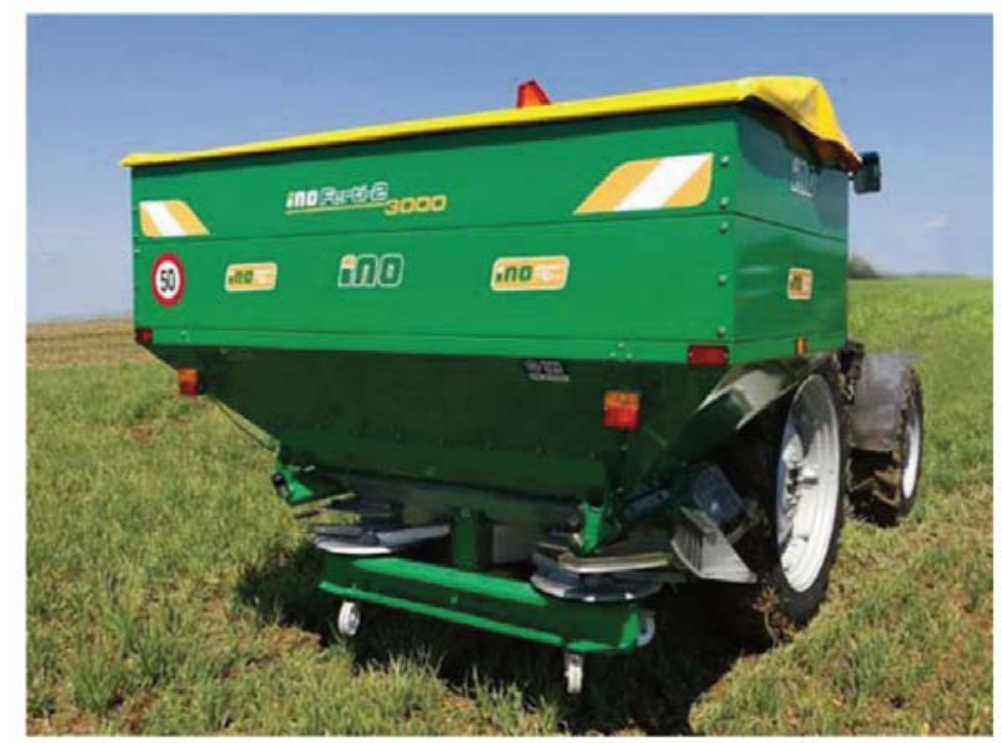

Figure 1. Double-disc mounted fertiliser spreader FERTI-2 (Source: INO)

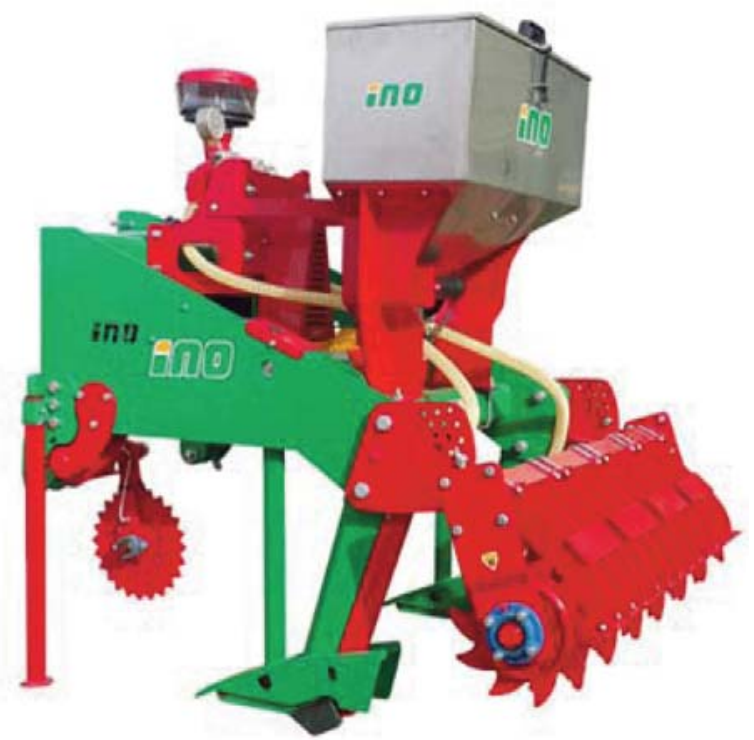

Figure 2. VVP 115 vibrational subsoiler with deep fertilizer device (Source: INO)

For a proper operation the system needs to get the speed of the tractor. This information is provided by ISO 11786 connector of the tractor or GPS speed sensor. Fertilizer calibration is the procedure, which has to be done just once for specific fertilizer (NPK, Urea, KAN...) ant it takes only ca. $10 \mathrm{~min}$. After this procedure is done, all necessary data are permanently stored in the electronic box and the work can begin.

The interface to the user is INO SmartAssist terminal (Figure 3) placed in the cabin of the tractor, which provides all necessary data on the graphic display. User can also change all necessary parameters from tractor cab.

Before work, the user just selects the fertilizer, which is actually in the hopper and desired spread density $(\mathrm{kg} / \mathrm{ha})$. When the user starts driving, the shutters are automatically open to the correct position. If the work 
speed changes, the shutter position also changes to meet requirements $(\mathrm{kg} / \mathrm{ha})$. When the tractor stops, the shutter closes automatically. The user can also additionally increase or decrease the quantity of fertilizer on the area directly by pressing button on the terminal without changing basic parameters stored.
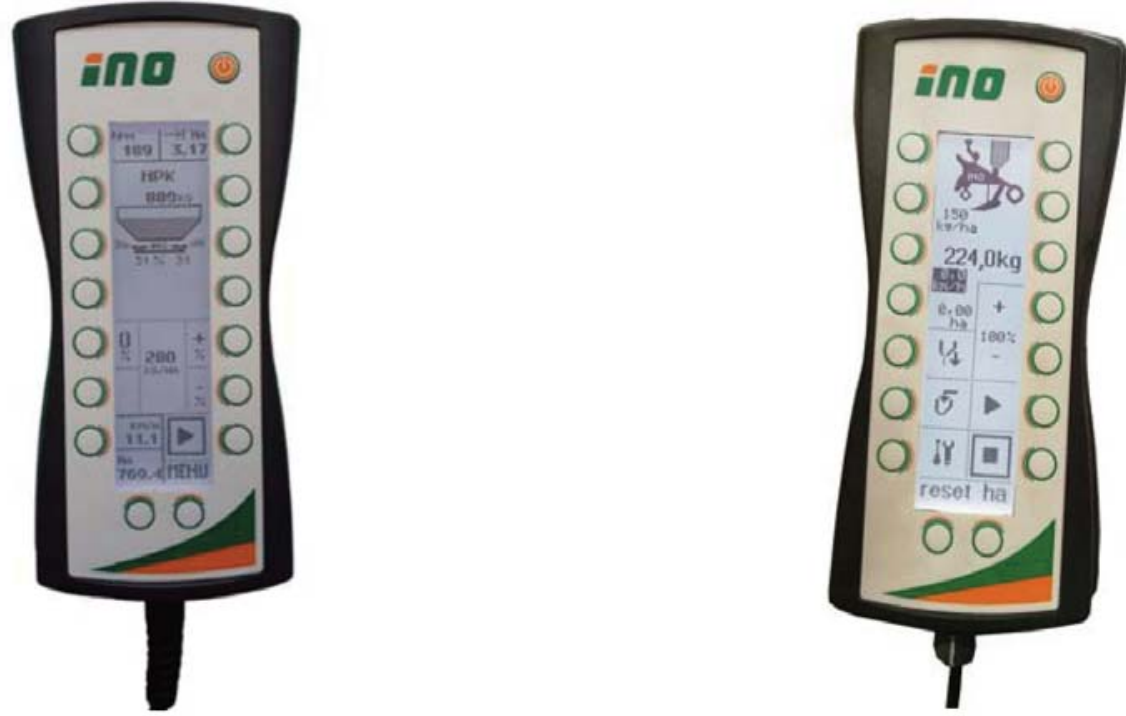

Figure 3. Innovations from INO's Electronic Development Laboratory - INO SmartAssist for FERTI-2 Fertilizer Spreader and for VVP 115 Vibrational Subsoiler with deep fertilizer device (Source: INO)

Additionally, the system provides simulation of the fertilizer quantity in the hopper (weight data in $\mathrm{kg}$ ). To use this feature, the user must enter the quantity of the fertilizer, which is added to the hopper before work. The real quantity of the fertilizer is measured by a TRUE Weighing System attached on the spreader (optionally) and connected with INO SmartAssist.

The side limiter (option) is also electrically driven, so the operator just presses the button and the limiter is placed onto the working position-on and back-off. (Žnideršič 2018)

The system also provides some other useful data:

1. Battery voltage

2. RPM of the discs

3. Hectares done

4. Residual hectares

5. Working hours

6. Recommendation for greasing every $8 \mathrm{~h}$

7. Working speed

Using this equipment, the farmer receives necessary information about production technology and about the safe operation of the machine, such as the amount of fertilizer dispensed, the amount of fertilizer in the tank, the speed of work, the size of the cultivated area, the amount of fertilizer that can be used in the tank, the number of hours worked, the battery charge level and the alerts for the machine maintenance.

\section{Winter Smart Flow}

Winter PK Smart is a spreader for salt and sand with electronics Winter Smart Flow and terminal SmartAssist. (Figure 4.)

The construction of the spreader consist of plastic hopper, rigid frame, stainless components for regulation, dosing and spreading, stainless deflector consisted of changeable flaps, gearbox with slower rotations and the electronic control SMART package. 
The SMART package includes:

- built in three electric actuators, used for:

- Opening-closing of a dosing flap

- Adjusting of the spreading width left (flaps on deflectors)

- Adjusting of the spreading width right (flaps on deflector)

- electronic system Winter Smart Flow together with a terminal SmartAssist for operating control with the following functions:

- Adjustment of the spreading width on the right and on the left side with lifting flaps on deflector

- Precise adjustment of the spreading density in $\mathrm{g} / \mathrm{m} 2$,

- Automatic adjustment of dosing flap according to the working speed

- Closing the dosing flap when stopped

- Measuring the distance travelled

- Showing the remaining weight of the product in the hopper - virtual weight,

- Availability for storing 10 different sorts of the spreading product (calibration),

- Intelligent calibration of the spreading product.

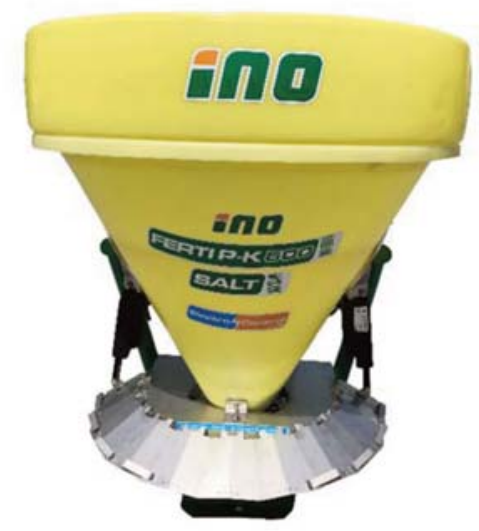

Figure 4. Winter PK Smart is a spreader for salt and sand with electronics Winter Smart Flow and terminal SmartAssist (Source: INO)

Electronics receives data regarding the tractor's speed via ISO 11786 (7-pin socket on the tractor) or GPS antenna or from the sensor on the wheel. (Žnideršič 2019)

INO SMART HOPPER on the flail mower Boxer

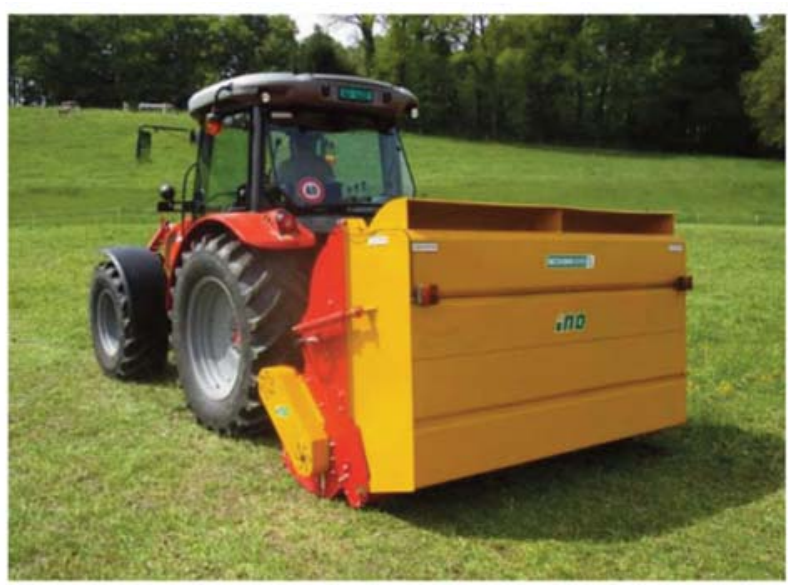

Figure 5. Flail mower INO Smart Hopper (Source: INO) 
Further, the company has proven INO Smart Hopper as a powerful tool for BOXER type collector containers. The device warns the user with sound and light signal when a container is fool. The control panel is easy to use. (Figure 5., 6.)

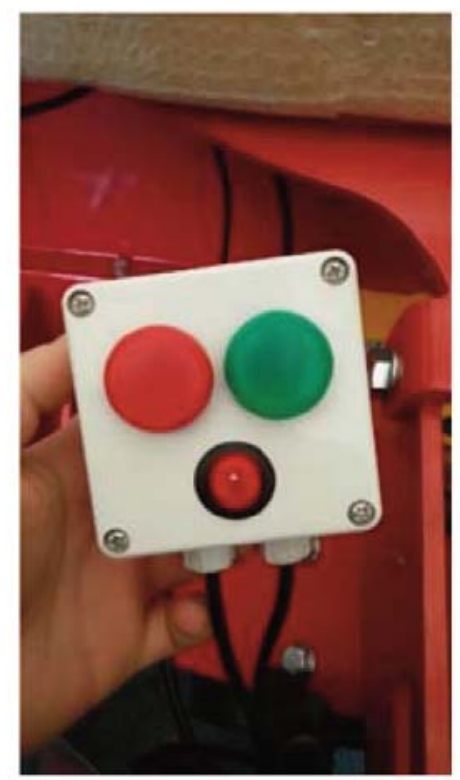

Figure 6. Control panel of INO Smart Hopper (Source: INO)

\section{Conclusions}

Precision Agriculture technologies have been developed all over the world to help the farmers increasing their crop yields and make agricultural production more profitable. This new developments resulted higher productivity and proved that this technology is very effective. Some of assistance systems, like autonomous track guidance, distribution control or side limiter are standard when investing in new agricultural machines, e. g. fertiliser spreader.

For small, medium-sized, and for the large-scale farm machinery too, the above-mentioned Smart Solutions prove to be beneficial for efficient work, professional utilization of machines and for minimizing the production and mechanization costs.

A common feature of systems described in this article is that they can be operated with or without from the tractor's ISOBUS system. The controller can be operated autonomously, using their own system, by the control panel (assistant) which is specially designed for this purpose.

The design of these electrical systems can also be well realized by an individual, innovative medium-sized machine manufacturing company, as it is shown in the presented work.

\section{References}

[1] Auernhammer H.: (2001) Precision Farming - the Environmental Challenge. Computers and Electronics in Agriculture. Vol 30. 1-3. pp 31-43.

[2] Auernhammer, H. (2002). Automatische Betriebsdatenerfassung im Ackerbau und seine Nutzenanwendung. In: "Ackerbau der Zukunft", Tagungsband zur Landtechnischen Jahrestagung am 04. Dezember 2002 in Deggendorf (G Wendl). Freising: Landtechn. Verein in Bayern (Landtechnik-Schrift, Nr. 14), pp. $45-58$

[3] Büdi K., Bucsi T., Szabó Sz., Veres Zs., Láng V.: (2018) Site Specific Fertilisation and Variable Rate Seeding for Optimized Maize Breeding in PREGA Science - Papers presented at the 2nd Sci. Conf. on Percision Agriculture and Agro-Informatics (Edited: Milics G.) p. 54-55. 
[4] Bullock D. G., Bullock D. S., Nafziger E. D., Doerge T. A., Paszkiewicz S. R., Carter P. R. et al.: (1998) Does Variable Rate Seeding of Corn Pay? Agronomy Journal 90 (6), 830-836.

[5] Clark R. L., McGuckin R. L.: (1996) Variable Rate Application Technology: An Overview. In Robert P. C., Rust R. H., Larson W. E. (editors), Precision Agriculture (pp. 855-862) Madison ASA/CSSA/SSSA

[6] Daberkow S. G., McBride W. D.: (1999) Adoption of Precision Agriculture by U.S. Corn producers, In Robert P. C., Rust R. H., Larson W. E. (editors), Precision Agriculture (pp. 1821-1831) Madison ASA/CSSA/SSSA

[7] Doluschitz, R., Morath, C., Pape, J. (2011): Agrarmanagement. Unternehmensführung in Landwirtschaft und Agribusiness. 1st ed. Stuttgart: UTB (Grundwissen Bachelor, 3587).

[8] Gibbons G.: (2000) Turning a Farm Art into Science / an Overview of Precision Farming. http://www.precisionfarming.com

[9] Kempenaar C. C. et al.: (2016) Towards Data-intensive, more Sustainable Farming: Advances in Predicting Crop Growth and Use of Variable Rate in Prediction Crop Growth and Use of Variable Rate Technology in Arable Crops in the Netherland. 13th International Conference on Precision Agriculture. July 31 - August 4. St Louis, USA.

[10] Kovács I., Husti I.: 2018. The Role of Digitalization in the Agricultural 4.0 - How to Connect the Industry 4.0 to Agriculture? Hungarian Agricultural Engineering, Periodical of the Committee of Agricultural and Biosystem Engineering of the Hungarian Academy of Sciences, Vol. 33. pp. 38-42.

[11] Lundström Ch., Lindblom J.: (2016) Considering Farmers' Situated Expertise in Using AgriDSS to Foster Sustainable Farming Practices in Precision Agriculture. 13th International Conference on Precision Agriculture. July 31 - August 4. St Louis, USA.

[12] Mackay D.: (1997) Precision Farming: Connecting the pieces. In D. A. Lobb (Ed.) Precision Farming. Challenges and Opportunities for Atlantic Canada. Charlottetown.

[13] Martinov M., Gronauer A., Košutić S.: (2018) Highlights of 27th Club of Bologna Meeting. Proceedings of the 46th International Symposium Actual Tasks on Agricultural Engineering. Opatija, Croatia, 27 February - 1 March 2018. p. 19 - 28.

[14] Mulla D. J.: (2013) Twenty Five Years of Remote Sensing in Precision Agriculture: Key Advances and Remaining Knowledge Gaps. Biosystems Engineering 114, 358-371.

[15] Nafziger E. D.: (2012) Corn in Illinois Agronomy Handbook. Champagne-Urbana. University of Illinois Extension and Outreach.

[16] Neményi M.: (2018) Research Activity in PA in the Last Decade in Terms of Sustainability (Thoughts about the Future). in PREGA Science - Papers presented at the 2nd Sci. Conf. on Percision Agriculture and Agro-Informatics (Edited: Milics G.) p. 12-16.

[17] Schellberg, J.; Hill, M., Gerhards, R., Rothmund, M., Braun, M. (2008): Precision agriculture on grassland. Applications, perspectives and constraints. In European Journal of Agronomy 29 (2-3), pp. 5971. DOI: $10.1016 /$ j.eja.2008.05.005.

[18] Šubic P.: (2017) Po kakovosti mulčerjev je INO Brežice med top 5, Časnik Finance, https://agrobiznis.finance.si/8856030/Po-kakovosti-mulcerjev-je-Ino-Brezice-med-top-5

[19] Takácsné Gy. K.: (2018) The Innovation Process of Precision Crop Production - Along with Economic Theories, in PREGA Science - Papers presented at the 2nd Sci. Conf. on Percision Agriculture and AgroInformatics (Edited: Milics G.) p .17-19.

[20] Taylor J., Whelan B.: (2010) A General Introduction to Precision Agriculture. Grains Research and Development Corporation. http://www. agripecisione.it

[21] Urso L-M. et al.: (2017) Crop Production of the Future-possible with a New Approach. Proceeding of Advances in Animal Biosciences: Precision Agriculture. Edinburgh, UK. pp. 734-737.

[22] Žnideršič J.: (2018) INO SMART Flow - Smart electronic for fertiliser spreader FERTI-2 Presentation, INO Brežice, Slovenia, Krška vas, 2. p.

[23] Žnideršič J.: (2019) INO Winter PK - spreader for salt and sand with electronic control, INO Brežice, Slovenia, Krška vas, 2. p. 